\title{
Técnicas de VATS Uniportal para Resseç̧ão Sublobar e Lobectomia Média: Desenvolvendo Diretrizes
}

\author{
Developing the Guidelines: The Techniques of Uniportal VATS for \\ Sublobar Resection and Middle Lobectomy \\ Ricardo Oliveira ${ }^{1 *}$ \\ ${ }^{1}$ Serviço de Cirurgia Torácica do Hospital Santa Izabel; Salvador, Bahia, Brasil
}

\section{Introdução}

Historicamente, a ressecção cirúrgica padrão para tratamento do Câncer de Pulmão de Não-Pequenas Células (CPNPC) é a lobectomia pulmonar. Em 1995, os resultados de estudo randomizado do Lung Cancer Study Group reforçaram esse conceito ao reportar aumento significativo de recorrência local e morte por câncer nos pacientes submetidos à ressecção sublobar (menor que um lobo pulmonar) comparados aos pacientes submetidos à lobectomia. ${ }^{1}$

Correspondence addresses: Dr. Ricardo Oliveira flaca@uol.com.br

Received: December 11, 2019

Revised: January 17, 2020

Accepted: January 21, 2020

Published: March 31, 2020

Data Availability Statement: All relevant data are within the paper and its Supporting Information files.

Funding: This work was the result of author's initiative. There was no support of research or publication funds.

Competing interests: The author has declared that no competing interests exist.

Copyright

(C) 2020 by Santa Casa de Misericórdia da Bahia. All rights reserved. ISSN: 2526-5563
Vieses de seleção podem ter interferido negativamente nos resultados em uma época na qual alguns exames atualmente essenciais no estadiamento do câncer de pulmão não eram disponíveis, como tomografia com emissão de pósitrons (PET) e ultrassonografia endobrônquica (EBUS). Apesar disso, desde a publicação deste estudo, a avaliação do papel da ressecção sublobar no tratamento do câncer de pulmão permaneceu adormecida por um longo tempo. No entanto, mais recentemente, esta temática voltou a ter destaque devido a um aumento na deteç̧ão de casos de câncer de pulmão em estágios precoces associado a uma melhoria dos exames de imagem e programas de rastreamento. ${ }^{2,3}$ Estas neoplasias precoces geralmente apresentam-se como nódulos não-sólidos em vidro despolido e semisólidos, histopatologicamente correspondendo a adenocarcinomas in situ e adenocarcinomas minimamente invasivos, respectivamente. ${ }^{4-6}$ Estudos não-randomizados mostram que a ressecção sublobar está indicada nestas lesões de melhor prognóstico, com baixo metabolismo no PET, assim como em pacientes com função pulmonar comprometida ou portadores de comorbidades que impossibilitam a realização de lobectomia. ${ }^{7-12}$ Dois ensaios clínicos randomizados multicêntricos em andamento avaliam a possibilidade de tornar a ressecção sublobar o tratamento padrão para

Resumo do Artigo: Arthur Vieira, Ricardo Oliveira, Ivan Salgado de Azevedo, Paula Ugalde Figueroa. Developing the guidelines: the techniques of uniportal VATS for sublobar resection and middle lobectomy. Article. Journal of Thoracic Disease Vol 11, Supplement 16 (September 2019). 
neoplasias pulmonares de até $2 \mathrm{~cm}$, causando um impacto significativo na prática clínica. ${ }^{13,14}$

Atualmente, a cirurgia minimamente invasiva vídeo-assitida (VATS) é a técnica de escolha para realização de lobectomias ou ressecções sublobares no tratamento do câncer de pulmão de estágio inicial.É necessário um conhecimento anatômico profundo e destreza de movimentos por parte do cirurgião para realização destas cirurgias com segurança. Nesse contexto, uma boa visualização do campo cirúrgico por vídeo é essencial. A técnica uniportal com colocação da câmera pela única incisão de trabalho (Figura 1) fornece uma visão frontal dos elementos do hilo pulmonar, facilitando a dissecção das estruturas. A publicação Developing the guidelines: the techniques of uniportal VATS for sublobar resection and middle lobectomy detalha a técnica das segmentectomias pulmonares anatômicas mais comuns e lobectomia média pela via uniportal. ${ }^{15}$ Neste artigo, faremos um resumo desta publicação.

\section{Avaliação Pré-Operatória}

Todos os pacientes devem realizar avaliação clínica com exames laboratoriais, cardiológicos e específicos na existência de comorbidades. A função pulmonar deve ser medida através de espirometria e capacidade de difusão de monóxido de carbono.

Do ponto de vista oncológico, deve-se realizar tomografia do tórax e abdome superior com contraste, PET, broncoscopia e, idealmente, biópsia da lesão para confirmação diagnóstica. Estadiamento invasivo do mediastino com EBUS ou mediastinoscopia está indicado na presença de linfonodos aumentados $(>1 \mathrm{~cm})$ ou hipermetabólicos ao PET. Uma análise minuciosa da tomografia do tórax para avaliar a relação da neoplasia com artéria, veia e brônquios segmentares é fundamental para decidir pela factibilidade da segmentectomia anatômica. O princípio oncológico primordial a ser respeitado é a margem oncológica do parênquima pulmonar. Para lesões muito próximas ao plano intersegmentar na tomografia, o exame intraoperatório das margens com congelação pode assegurar sua adequabilidade.

\section{Cirurgia}

Alguns aspectos são comuns a todas as segmentectomias como: anestesia geral, ventilação monopulmonar com tubo duplolúmen, posicionamento do paciente em decúbito lateral, incisão de $3-4 \mathrm{~cm}$ no $5^{\circ}$ espaço intercostal nas segmentectomias dos lobos superiores e lobectomia média e no $6^{\circ}$ espaço intercostal nas segmentectomias dos lobos inferiores, linfadenectomia, bloqueio de nervo intercostal preemptivo e, ao término da cirurgia, utilização de dispositivo alargador de incisão (Figura 1) para facilitar a exposição e retirada da peça de forma protegida.

\section{Segmentectomia Posterior (S2) do Lobo Superior Direito(LSD)}

O pulmão é tracionado anteriormente e a dissecção é iniciada no hilo pulmonar posteriormente ao longo do brônquio intermédio até a origem do brônquio do LSD e suas segmentações. Em seguida, a artéria pulmonar é identificada na cissura e dissecada no sentido posterior. O grampeamento da cissura obliqua posterior e a retirada de linfonodos permitem melhor exposição da artéria pulmonar. O LSD é tracionado no sentido apical e a artéria ascendente posterior e a veia para o segmento posterior do LSD são individualizadas e grampeadas ou seccionadas e seladas com dispositivos de energia para vasos de até $7 \mathrm{~mm} .16$ Por fim, o brônquio de S2 é identificado e grampeado com auxílio de broncoscopia intra-operatória. Neste momento, é realizada insuflação do pulmão direito, o segmento S2 permanece atelectasiado e o plano intersegmentar parenquimatoso é delimitado e grampeado. A peça é retirada de forma protegida e é feito bloqueio intercostal. 
Figura 1. Acesso uniportal no $5^{\circ}$ espaço intercostal direito com dispositivo alargador de incisão.

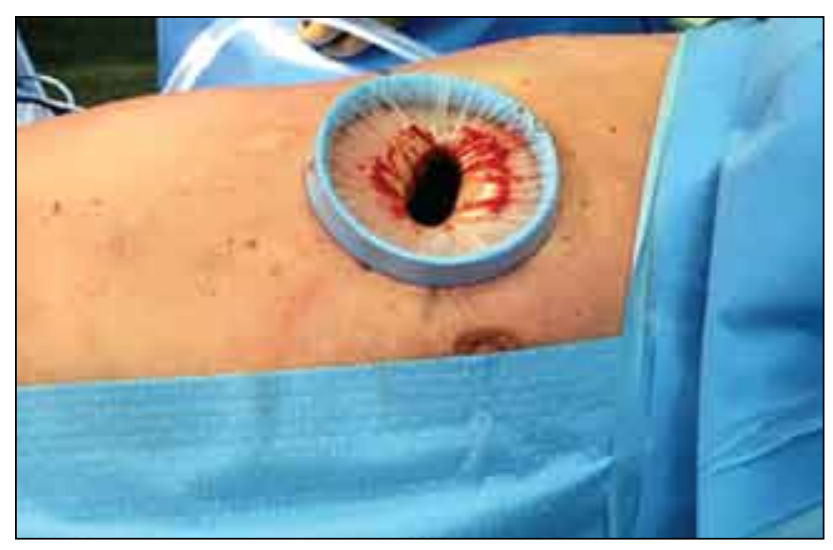

\section{Tri-Segmentectomia $(\mathrm{S} 1+2+\mathrm{S3})$ do Lobo Superior Esquerdo (LSE)}

Na tri-segmentectomia do LSE são ressecados os segmentos ápico-posterior $(\mathrm{S} 1+2)$ e anterior $(\mathrm{S} 3)$, preservando-se a língula $(\mathrm{S} 4+5)$. Adissecção inicia-se no hilo pulmonar anteriormente ao nível da veia pulmonar superior. São identificadas as veias de cada segmento do LSE e realizado grampeamento, mantendo-se o ramo lingular. $\mathrm{Na}$ sequência, os ramos arteriais para os segmentos $\mathrm{S} 1+2$ e S3 são isolados e grampeados. É importante reconhecer as frequentes variações anatômicas dos ramos da artéria pulmonar para o LSE a fim de evitar ligaduras inadvertidas. O LSE é tracionado para manter o brônquio em posição vertical, facilitando a correta identificação da divisão brônquica segmentar. Os brônquios dos segmentos $\mathrm{S} 1+2$ e S3 são grampeados. O plano intersegmentar com a língula é seccionado com endogrampeador conforme técnica de insuflação pulmonar descrita anteriormente. A peça é retirada de forma protegida e é feito bloqueio intercostal.

\section{Lingulectomia}

Assim como na tri-segmentectomia, a dissecção é iniciada no hilo anterior com intuito de identificar a veia pulmonar superior e seus ramos. A pleura mediastinal é aberta entre as veias pulmonares superior e inferior. A veia da língula é ligada com grampeamento. Diferente da tri-segmentectomia, na lingulectomia há necessidade de grampeamento da cissura oblíqua para exposição da artéria pulmonar interlobar e seus ramos. A artéria lingular é grampeada com carga vascular. Em geral, o brônquio lingular localiza-se posterior à veia lingular já seccionada. Broncoscopia intraoperatória pode auxiliar na identificação deste brônquio o qual é grampeado. O plano intersegmentar segue as mesmas etapas já descritas.

\section{Lobectomia Média}

A primeira etapa da lobectomia média é a dissecção da veia pulmonar superior e correta identificação da veia do lobo médio. Na técnica uniportal, para grampeamento da veia do lobo médio, a melhor forma é posicionar o grampeador no sentido do mediastino posteriormente, abaixo do brônquio do lobo médio. Nesta manobra, manter o pulmão tracionado e a veia em posição verticalizada permite avançar o grampeador de forma segura mesmo sem visualização completa da ponta. Em seguida, separam-se os lobos inferior do médio com grampeamento da cissura obliqua anterior. $\mathrm{O}$ brônquio do lobo médio fica bem exposto e é grampeado. É feita ligadura de 1 ou 2 ramos da artéria pulmonar para o lobo médio com endogrampeador. Para finalizar, a cissura horizontal entre o LSD e LM é seccionada.

\section{Segmentectomiasuperior (S6) do Lobo Inferior}

O primeiro passo é identificar a artéria pulmonar interlobar na cissura. Caso esta seja incompleta, explora-se o espaço entre as veias pulmonares superior e inferior, identifica- 
se a carina brônquica secundária e a artéria estará logo acima. Isso permite confeccionar um "túnel" entre a artéria e cissura. Em seguida, o grampeamento da cissura expõe completamente a artéria interlobar e seus ramos. Nesta sequência, a artéria e o brônquio do segmento são grampeados. Após secção do brônquio, a veia do segmento 6 é identificada e esta pode ser grampeada individualmente ou em bloco com o plano intersegmentar.

\section{Segmentectomia Basilar (S7, S8, S9, S10) do Lobo Inferior}

A estratégia inicial depende da disposição da cissura. Se a cissura for incompleta, a dissecção começa pela secção do ligamento pulmonar inferior, abertura da pleura mediastinal posterior e dissecção da veia pulmonar inferior. Em seguida, faz-se a dissecção anterior entre as veias pulmonares até exposição da carina secundária e identificação da artéria interlobar na cissura (já anteriormente descrita). Procede-se com grampeamento da cissura acima da artéria pulmonar. Dessa forma, são identificados os ramos arteriais do lobo inferior e faz-se a ligadura da artéria basilar com endogrampeador e carga vascular.

Em caso de cissura completa, a artéria interlobar é facilmente identificada na cissura e a primeira etapa é a ligadura dos ramos basilares.

Após a ligadura da artéria, segue-se com grampeamento do brônquio dos segmentos basilares e por último da veia pulmonar segmentar com atenção especial para preservar o ramo venoso do segmento superior. A secção do plano intersegmentar finaliza o procedimento.

\section{Conclusão}

As segmentectomias anatômicas exigem elevado conhecimento anatômico e domínio de técnicas de cirurgia minimamente invasiva.
O artigo "Developing the guidelines: the techniques of uniportal VATS for sublobar resection and middle lobectomy" descreve as etapas das principais segmentectomias anatômicas e lobectomia média por via uniportal, com objetivo de padronização da técnica. Cirurgiões torácicos devem estar envolvidos com treinamento dessas cirurgias visto que certamente ressecções sublobares serão cada vez mais necessárias.

\section{Referências}

1. Ginsberg RJ, Rubinstein LV. Randomized trial of lobectomy versus limited resection for T1 N0 nonsmall cell lung cancer. Lung Cancer Study Group. Ann Thorac Surg. 1995;60:615-22; discussion 622-3.

2. Tammemagi MC, Schmidt $\mathrm{H}$, Martel $\mathrm{S}$ et al. Participant selection for lung cancer screening by risk modelling (the Pan-Canadian Early Detection of Lung Cancer [PanCan] study): a single-arm, prospective study. Lancet Oncol. 2017;18:1523-31.

3. Dutch Belgian randomised lung cancer screening trial (NELSON). Available online: https://doi.org/10.1186/ ISRCTN63545820.

4. Travis WD, Brambilla E, Noguchi M et al. International Association for the Study of Lung Cancer/American Thoracic Society/European Respiratory Society International Multidisciplinary Classification of Lung Adenocarcinoma. J Thorac Oncol. 2011;6:244-85.

5. Godoy MC, Truong MT, Sabloff B et al. Subsolid pulmonary nodule management and lung adenocarcinoma classification: state of the art and future trends. Semin Roentgenol. 2013;48:295-307.

6. Detterbeck FC, Boffa DJ, Kim AW et al. The Eighth Edition Lung Cancer Stage Classification. Chest. 2017;151:193-203.

7. National Comprehensive Cancer Network. NonSmall Cell Lung Cancer. Version 01.2019. Available online:https://www.nccn.org/professionals/physician_ gls/pdf/ nscl.pdf. Accessed on Nov 18, 2018.

8. Altorki NK, Kamel MK, Narula $\mathrm{N}$ et al. Anatomical segmentectomy and wedge resections are associated with comparable outcomes for patients with small cT1N0 non- small cell lung cancer. J Thorac Oncol. 2016;11:1984-92.

9. Nakamura H, Taniguchi $\mathrm{Y}$, Miwa $\mathrm{K}$ et al. Comparison of the surgical outcomes of thoracoscopic lobectomy, segmentectomy, and wedge resection for clinical stage I non-small cell lung cancer. Thorac Cardiovasc Surg. 2011;59:137-41. 
10. Martin-Ucar AE, Nakas A, Pilling JE et al. A casematched study of anatomical segmentectomy versus lobectomy for stage I lung cancer in high-risk patients. Eur J Cardiothorac Surg. 2005;27:675-9.

11. El-Sherif A, Gooding WE, Santos R et al. Outcomes of sublobar resection versus lobectomy for stage I nonsmall cell lung cancer: a 13-year analysis. Ann Thorac Surg. 2006;82:408-15; discussion 415-6.

12. Donahue JM, Morse CR, Wigle DA et al. Oncologic efficacy of anatomic segmentectomy in stage IA lung cancer patients with T1a tumors. Ann Thorac Surg. 2012;93:381-7; discussion 387-8.

13. Comparison of Different Types of Surgery in Treating Patients With Stage IA Non-Small Cell Lung Cancer. https://clinicaltrials.gov/ct2/show/NCT00499330.
14. Nakamura K, Saji H, Nakajima R et al. A phaseIII randomized trial of lobectomy versus limited resection for small-sized peripheral non-small cell lung cancer (JCOG0802/WJOG4607L). Jpn J Clin Oncol. 2010;40:271-4.

15.Vieira A, Oliveira R, de Azevedo IS, Figueroa PU. Developing the guidelines: the techniques of uniportal VATS for sublobar resection and middle lobectomy. J Thorac Dis. 2019;11(Suppl 16):S2086-S2094. doi: 10.21037/ jtd.2019.04.88.

16.Goudie E, Oliveira RL, Thiffault V et al. Phase 1 trial evaluating safety of pulmonary artery sealing with ultrasonic energy in VATS lobectomy. Ann Thorac Surg. 2018;105:214-20. 